ORIGINAL ARTICLE

\title{
UEFA Champions League study: a prospective study of injuries in professional football during the 2001-2002 season
}

\author{
M Waldén, $M$ Hägglund, J Ekstrand
}

Br J Sports Med 2005;39:542-546. doi: 10.1136/bjsm.2004.014571

See end of article for authors' affiliations

Correspondence to

Dr Waldén, Department of

Health and Society,

Linköping University,

S-581 83 Linköping,

Sweden; markus.walden@

telia.com

Accepted

23 November 2004 ult football involving several different countries has investigated the Background: No previous study on adult football involving several differe
incidence and pattern of injuries at the highest club competitive level.

Objective: To investigate the risk exposure, risk of injury, and injury pattern of footballers involved in UEFA Champions League and international matches during a full football season.

Method: Eleven top clubs (266 players) in five European countries were followed prospectively throughout the season of 2001-2002. Time-lost injuries and individual exposure times were recorded during all club and national team training sessions and matches.

Results: A total of 658 injuries were recorded. The mean (SD) injury incidence was 9.4 (3.2) injuries per 1000 hours (30.5 (11.0) injuries per 1000 match hours and 5.8 (2.1) injuries per 1000 training hours). The risk of match injury was significantly higher in the English and Dutch teams than in the teams from France, Italy, and Spain (41.8 (3.3) v 24.0 (7.9) injuries per 1000 hours; $p=0.008$ ). Major injuries (absence $>4$ weeks) constituted $15 \%$ of all injuries, and the risk of major injury was also significantly higher among the English and Dutch teams $(p=0.04)$. National team players had a higher match exposure, with a tendency towards a lower training injury incidence than the rest of the players $(p=$ $0.051)$. Thigh strain was the most common injury (16\%), with posterior strains being significantly more common than anterior ones (67 $\vee 36 ; p<0.0001)$.

Conclusions: The risk of injury in European professional football is high. The most common injury is the thigh strain typically involving the hamstrings. The results suggest that regional differences may influence injury epidemiology and traumatology, but the factors involved are unclear. National team players have a higher match exposure, but no higher risk of injury than other top level players.
A ccording to UEFA (Union des Associations Europeénnes de Football), there are around 20 million licensed footballers in Europe. Several studies reporting the injury epidemiology and traumatology of male adult football at elite or professional level in Europe have all confirmed a high risk of injury. ${ }^{1-13}$ The successful top clubs play several matches in domestic leagues and cups as well as in the Champions League or UEFA Cup. The number of competitive matches was further increased in the 1999-2000 season when a second group stage was added to the Champions League. Many of the top players also play for their national team, and it has been speculated that this increase in match exposure may be accompanied by a higher risk of injury.

No study has so far purely investigated teams at the highest possible competitive club level or has included teams from many countries. It is therefore unclear whether the risk of injury is even higher or if there are any regional differences in the injury characteristics. However, one study on junior football compared the injury epidemiology between two different European regions without showing any differences at all between the closely situated Czech Republic and the Alsace region of Germany and France. ${ }^{14}$ Another recent study on male adult football compared the Swedish and Danish top divisions and noted that the risk of injury during training and risk of major injury were significantly higher among the Danish teams, suggesting that regional differences may have an impact on injury epidemiology. ${ }^{10}$

This study is the first to investigate the injury characteristics among top clubs from several countries including play in the Champions League and national teams. The purpose was to investigate the risk exposure, risk of injury, and injury pattern during a full football season. Our hypotheses were that (a) there are regional differences influencing the risk of injury and $(b)$ national team players have a higher risk exposure and higher risk of injury than the rest of the players.

\section{MATERIALS AND METHODS}

\section{Study sample and study period}

A prospective cohort study of European professional football was carried out during the 2001-2002 season (1 July to 15 May). The season consisted of pre-season (July to August) and competitive season (September to May). All competitive matches were played on natural grass. In the year 2000, 14 clubs from the top divisions of seven countries were asked by UEFA to participate in the study. Two clubs refused participation, and one club was excluded because of missing injury and exposure data, which was due to a change of club doctors during the season. The 11 clubs included were: Arsenal FC and Manchester United FC (England); Paris Saint-Germain FC, Stade Rennais FC, and RC Lens (France); AC Milan, Juventus FC, and FC Internazionale (Italy); AFC Ajax and PSV Eindhoven (the Netherlands); Real Madrid CF (Spain).

All players in the first team squads were invited during the first month of the study (July) to participate. Players injured at the start of the study were included, but their injuries were not taken into account. Players contracted to the teams after July were not included. In total, 266 of 269 players were included, and signed informed consent was obtained. Two players did not give their consent at the start of the study, and one player withdrew his consent after two months. During the season, 30 players $(11 \%)$ dropped out because of transfer, and data from these players are included for their time of participation. 


\begin{tabular}{|c|c|}
\hline Sprain & Acute distraction injury of ligaments or joint capsules \\
\hline Joint injury & Acute isolated chondral or meniscus lesion \\
\hline Strain & Acute distraction injury of muscles and tendons \\
\hline Contusion & $\begin{array}{l}\text { Tissue bruise without concomitant injuries classified } \\
\text { elsewhere }\end{array}$ \\
\hline Fracture & Traumatic break of bone \\
\hline Dislocation & $\begin{array}{l}\text { Partial or complete displacement of the bony parts of a } \\
\text { joint }\end{array}$ \\
\hline Other & $\begin{array}{l}\text { Injuries not classified elsewhere. Examples: wound, } \\
\text { concussion, etc }\end{array}$ \\
\hline
\end{tabular}

\section{Exposure and injuries}

Individual exposure in minutes for all training sessions and matches with the club and national team was recorded on a standard attendance record sheet. One of the club doctors was responsible for recording each injury, and at least one member of the medical team attended training sessions and matches. All injuries were recorded immediately after the event on a standard injury card, and cards were sent in each month together with the attendance record. The injury card provided information on the date of injury, scheduled activity, type, location, side, reinjury, and foul play. Each injury was followed until the final day of rehabilitation. The injuries were classified into four categories of severity according to the length of absence from training sessions and matches including the day of injury: slight $(\leqslant 3$ days), minor (4-7 days), moderate (8-28 days), and major ( $>28$ days). Injuries occurring during leisure time or other sports were not counted.

\section{Definitions}

A training session was defined as any coach directed scheduled physical activity carried out with the team. A match was defined as any scheduled friendly or competitive match with the club or national team. Injury was defined as described by Ekstrand ${ }^{15}$ as any injury occurring during a scheduled training session or match causing the player to miss the next training session or match. A player was considered fully rehabilitated when the club medical officer allowed full participation in collective team training sessions or match play. Traumatic injuries were characterised by acute onset (table 1). The definition of overuse injury was modified from Orava ${ }^{16}$ and defined as a pain syndrome of the musculoskeletal system with insidious onset and without any known trauma or disease that might have given previous symptoms. Reinjury was defined as an identical injury (same side, type, and location) within two months of the final rehabilitation day of the previous injury. Foul play was defined according to the decision of the referee (own or opponent foul) and was reported by the contact person for the match injuries. To reduce bias in data collection, all clubs were provided with a manual containing information about the study design and definitions including fictive examples and scenarios.

\section{Statistical analysis}

Differences in anthropometric data were analysed using one way factorial analysis of variance. Differences in injury incidence between training and match and between preseason and competitive season were analysed using the Wilcoxon signed rank test. Regional differences as well as comparisons between national team players and the rest of the players were analysed with the Mann-Whitney U test. The difference in thigh strain location was analysed using the $\chi^{2}$ test. Comparison of length of absence between reinjuries and initial injuries was analysed using the Wilcoxon signed rank test, and the Mann-Whitney U test was used when comparing length of absence between overuse and traumatic injuries. The significance level was set at $5 \%(\mathrm{p}<0.05)$. Results are expressed as mean (SD).

\section{RESULTS}

The mean age was 26 (4) years, mean height was $181(6) \mathrm{cm}$, and mean body mass was 78 (7) $\mathrm{kg}$. There were no differences between the teams in age $(\mathrm{p}=0.06)$ or height $(p=0.06)$, but there were several interteam differences in weight $(\mathrm{p}=0.006)$. Nine of the participating clubs qualified for the Champions League 2002-2003, and one club for the UEFA Cup 2002-2003.

\section{Exposure and risk of injury}

The total exposure was 69707 hours (58 149 training hours and 11558 match hours). Table 2 shows the detailed exposure data. The highest number of matches for a single player was 69 . In total, $85 \%$ of the players $(225 / 266)$ incurred

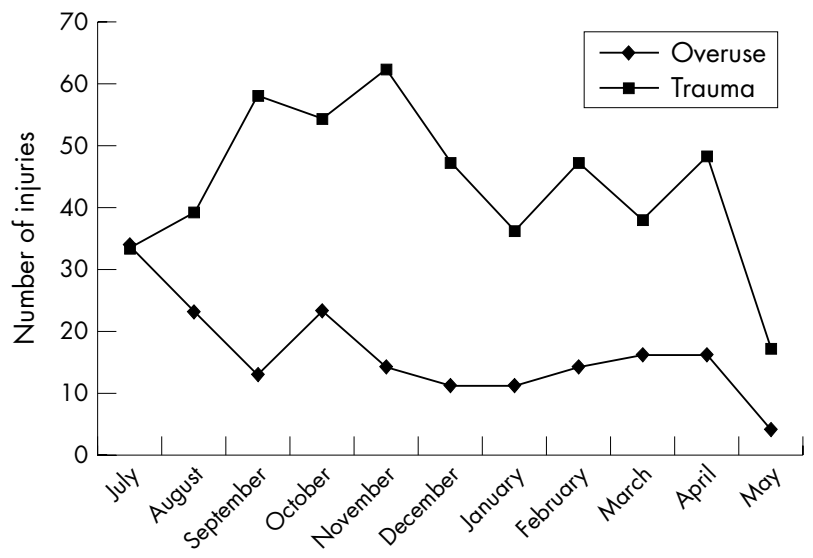

Figure 1 Seasonal distribution of traumatic and overuse injuries in elite European professional footballers. Pre-season = July to August; competitive season $=$ September to May.

Table 2 Exposure data for elite European professional footballers

\begin{tabular}{lllll}
\hline & Mean & SD & $95 \% \mathbf{C l}$ & Range \\
\hline $\begin{array}{l}\text { Training sessions } \\
\text { No/team }\end{array}$ & 230 & 28 & 211 to 249 & $\begin{array}{l}181-288 \\
\text { No/player }\end{array}$ \\
$\begin{array}{l}\text { Matches } \\
\text { No/team }\end{array}$ & 174 & 53 & 167 to 180 & $0-266$ \\
$\quad$ No/player & 59 & 9 & 52 to 65 & $40-76$ \\
$\begin{array}{l}\text { Training sessions and matches } \\
\text { No/team } \\
\text { No/player }\end{array}$ & 36 & 16 & 34 to 38 & $0-69$ \\
\hline & 289 & 25 & 272 to 305 & $257-352$ \\
& 210 & 64 & 202 to 218 & $0-317$ \\
\hline & & & &
\end{tabular}




\begin{tabular}{|c|c|c|c|c|}
\hline & \multirow[b]{2}{*}{ No of injuries } & \multicolumn{3}{|c|}{ Injury incidence } \\
\hline & & Mean & SD & $95 \% \mathrm{Cl}$ \\
\hline \multicolumn{5}{|l|}{ Training } \\
\hline Pre-season & $75(11)$ & 5.2 & 3.7 & 2.7 to 7.6 \\
\hline Competitive season & 223 (34) & 4.8 & 2.2 & 3.4 to 6.3 \\
\hline Total season & $298(45)$ & 5.8 & 2.1 & 3.6 to 6.4 \\
\hline \multicolumn{5}{|l|}{ Match } \\
\hline Pre-season & $54(8)$ & 28.6 & 15.0 & 18.5 to 38.7 \\
\hline Competitive season & $306(47)$ & 30.9 & 12.1 & 22.8 to 39.0 \\
\hline Total season & $360(55)$ & 30.5 & 11.0 & 23.1 to 37.9 \\
\hline \multicolumn{5}{|l|}{ Total } \\
\hline Pre-season & $129(20)$ & 8.2 & 3.5 & 5.8 to 10.5 \\
\hline Competitive season & $529(80)$ & 9.7 & 3.9 & 7.1 to 12.3 \\
\hline Total season & $658(100)$ & 9.4 & 3.2 & 7.3 to 11.5 \\
\hline
\end{tabular}

658 injuries. Figure 1 shows the injury time distribution. Table 3 shows the numbers of injuries and the risk of injury. There were no differences in injury incidence between the pre-season and the competitive season.

During the study period, 148 players $(56 \%)$ were exposed to some form of national team play on at least one occasion, and almost $4 \%$ of all injuries (23/658) occurred under these circumstances. These national team players played significantly more matches than the rest of the players (42 $v 28$; $\mathrm{p}<0.001)$, but there was no difference in the amount of training ( $176 v 171 ; \mathrm{p}=0.79)$. There was a tendency towards a lower training injury incidence between the national team players and the rest of the players (4.1 (2.4) $v 6.2$ (2.7) injuries per 1000 hours; $p=0.051)$, but there was no difference in match play (27.2 (12.2) v 33.8 (21.5) injuries per 1000 hours; $\mathrm{p}=0.15$ ).

\section{Injury types and locations}

As shown in table $4,85 \%$ of the injuries affected the lower extremities. Table 5 shows the injury types. The single most common injury subtype was thigh strain, representing $16 \%$ $(103 / 658)$ of all injuries. Posterior thigh strains were significantly more common than anterior thigh strains (67 $v 36$ injuries; $\mathrm{p}<0.0001)$. Most $(82 \%)$ of the strains were located in the thigh $(61 \%)$ or groin $(21 \%)$ region. Nine out of ten sprains were located in the ankle (51\%) or knee joints (39\%). Isolated injury to the medial collateral ligament was the most common knee sprain, constituting 53\% (29/55) of all knee sprains. The most common overuse injuries were low back pain (23/179), Achilles tendinopathy (21/179), adductor related groin pain (18/179), and patellar tendinopathy (13/179).

\section{Injury severity and reinjuries}

Table 6 shows injury severity. One third of the major injuries (33/97) were located in the knee. Only $13 \%$ of the major injuries were due to overuse, and traumatic injuries resulted in a significantly longer mean absence than overuse injuries (21.1 (36.8) v 11.4 (24.5) days; $\mathrm{p}<0.0001)$. Reinjuries constituted $15 \%(101 / 658)$ of all injuries, and nearly two thirds $(61 \%)$ of them were overuse injuries. For 14 reinjuries, the corresponding initial injury was before the start of the study, and the length of absence resulting from these initial injuries is not known. There was no difference in the mean length of absence between the reinjuries with adequate initial injury absence data (87/101) and the initial injuries (12.4 (22.1) v 13.0 (21.2) days; $\mathrm{p}=0.95)$.

\section{Foul play}

About a quarter of the match injuries $(23 \% ; 83 / 360)$ were due to foul play, and all of them were due to opponent foul. The foul play injuries were all of traumatic origin and consisted mainly of contusions (46\%) and sprains (37\%). Only one of the strains was due to foul play. More than every fourth major match injury (17/64) was caused by opponent foul play, and these injuries consisted predominantly of sprains (10/17) and fractures (4/17).

\section{Regional differences}

The Spanish team had the highest number of matches (76), and one of the French teams had the lowest number of matches (40) during the season. The mean match injury incidence among the four English and Dutch teams was significantly higher than for the seven Mediterranean teams $(41.8$ (3.3) $v 24.0$ (7.9) injuries per 1000 exposure hours; $\mathrm{p}=$ $0.008)$, but there was no difference in the mean training injury incidence $\left(\begin{array}{lllll}6.0 & (1.5) & v & 4.9 & (2.2)\end{array}\right)$ injuries per 1000 exposure hours; $\mathrm{p}=0.26$ ). The risk of major injury was also significantly higher among the English and Dutch teams (2.0 (0.5) $v$ l.1 (0.6) injuries per 1000 exposure hours; $\mathrm{p}=0.04)$. The three French teams had a significantly lower risk of

Table 4 Injury locations and severity in elite European professional footballers

\begin{tabular}{llllll} 
& Injuries & Slight & Minor & Moderate & Major \\
\hline Head/face/neck & $22(3)$ & $11(6)$ & $7(4)$ & $4(2)$ & $0(0)$ \\
Back & $41(6)$ & $18(10)$ & $17(9)$ & $4(2)$ & $2(2)$ \\
Hip/groin & $79(12)$ & $22(12)$ & $24(13)$ & $24(12.5)$ & $9(9)$ \\
Thigh & $152(23)$ & $36(20)$ & $46(24.5)$ & $55(28.5)$ & $15(15.5)$ \\
Knee & $131(20)$ & $40(22)$ & $26(14)$ & $32(16.5)$ & $33(34)$ \\
Lower leg & $73(11)$ & $25(14)$ & $16(8.5)$ & $22(11.5)$ & $10(10.5)$ \\
Ankle & $89(14)$ & $18(10)$ & $28(15)$ & $31(16)$ & $12(12.5)$ \\
Foot & $35(5.5)$ & $9(5)$ & $5(3)$ & $11(6)$ & $10(10.5)$ \\
Other & $36(5.5)$ & $3(2)$ & $17(9)$ & $10(5)$ & $6(6)$ \\
Total & $658(100)$ & $182(100)$ & $186(100)$ & $193(100)$ & $97(100)$ \\
\hline & \multicolumn{7}{|l}{ Values in parentheses are percentages. Approximation of the percentages has been made to equal 100\%. } \\
\hline
\end{tabular}


Table 5 Injury types and severity in elite European professional footballers

\begin{tabular}{llllll}
\hline & Injuries & Slight & Minor & Moderate & Major \\
\hline Sprain & $141(21)$ & $21(11.5)$ & $35(19)$ & $48(25)$ & $37(38)$ \\
Joint injury & $11(2)$ & $0(0)$ & $0(0)$ & $4(2)$ & $7(7.5)$ \\
Strain & $169(26)$ & $23(13)$ & $51(27.5)$ & $72(37)$ & $23(24)$ \\
Contusion & $105(16)$ & $40(22)$ & $41(22)$ & $22(11)$ & $2(2)$ \\
Fracture & $16(2)$ & $1(0.5)$ & $1(0.5)$ & $3(2)$ & $11(11)$ \\
Dislocation & $6(1)$ & $0(0)$ & $2(1)$ & $2(1)$ & $2(2)$ \\
Other & $31(5)$ & $10(5)$ & $9(5)$ & $10(5)$ & $2(2)$ \\
Overuse & $179(27)$ & $87(48)$ & $47(25)$ & $32(17)$ & $13(13.5)$ \\
Total & $658(100)$ & $182(100)$ & $186(100)$ & $193(100)$ & $97(100)$ \\
\hline & \multicolumn{2}{l}{ Values in parentheses are percentages. Approximation of the percentages has been made to equal 100\%. }
\end{tabular}

injury due to foul play compared with the rest of the teams (1.1 (1.9) $v 8.6$ (5.3) injuries per 1000 exposure hours; $\mathrm{p}=$ $0.04)$.

\section{DISCUSSION}

The principal findings in this study were that the incidence and pattern of injuries differed between teams from different regions, and players who were exposed to national team play had a higher match exposure. However, the higher match exposure did not influence the risk of injury when comparing these players with those who did not have international obligations. Another main finding was that thigh strain was the most common injury, typically involving the hamstring muscles.

\section{Incidence and pattern of injuries}

The injury incidence in this study is consistent with recent studies at elite or professional level using a similar or identical time-lost injury definition. ${ }^{1}{ }^{72}$ In these studies, the injury incidence has been reported to be between 3.4 and 5.9 injuries per 1000 training hours and 25.9 and 34.8 injuries per 1000 match hours. In another recent study on the Swedish national team, the injury incidence was found to be 5.8 injuries per 1000 training hours and 30.3 injuries per 1000 match hours, which is almost identical with the findings in the present study. ${ }^{4}$ However, the time-lost match injury incidence in amateur football of different playing levels is reported to be between 11.9 and 16.9 injuries per 1000 match hours. ${ }^{37-18}$ It seems therefore that, when defining injury according to time loss, the match injury incidence increases with the playing level, reaching some form of plateau around 30 injuries per 1000 match hours at the highest club or international level.

The consequences of a tight match schedule for top players have been evaluated in a study on the World Cup tournament in Korea/Japan 2002. ${ }^{5}$ In that study, conducted on the same cohort as in the current study, the World Cup players had no higher risk of injury than the rest of the players. This is consistent with the findings in this study, where the players exposed to international duties during the season did not have a higher risk of injury than the rest of the top level players. However, there was a tendency $(p=0.051)$ towards a lower training injury incidence among the national team players, which may possibly be explained by the fact that injured players are usually excluded from the national team. Other possible factors may be that international players are fitter and more technically skilled than the rest of the players and/or that they are performing more recovery or preventive training during the season because of their tighter match schedule.

The finding in this study that the risk of injury may differ between countries is supported by another study in which injury incidence and injury pattern were compared between the elite divisions in Denmark and Sweden. ${ }^{10}$ The four English and Dutch teams in our study showed a higher risk of match injury and major injury than the other teams. The influence of regional differences on the risk of injury may be ascribed to several factors such as differences in seasonal compositions, play intensity, playing style, tactics, referee judgments, weather and pitch conditions, or the way the medical staff work. None of these factors were evaluated in this study, but the influence of weather and ground conditions has been discussed in some studies. ${ }^{13^{19-22}}$ More highly skilled players have been shown to suffer more injuries in good (dry) weather, whereas those with lower skill levels suffer more injuries in bad (rain or snow) weather conditions, ${ }^{17}$ and traumatic injuries have been associated with rough or slippery surfaces caused by rain, snow, or ice among Swedish amateur players. ${ }^{19}$ Moreover, referee standards and decisions have been evaluated in a few recent studies, ${ }^{23}{ }^{24}$ but the influence of regional differences in referee decisions and rule interpretation is so far unclear. In this study, it was found that about $25 \%$ of all match injuries were due to foul play, and the three French teams had a significantly lower risk of match injury from foul play than the other teams.

Thigh strain was the single most common injury subtype, which is in agreement with studies on English, Icelandic, Swedish, and Danish elite football. ${ }^{781012}$ In English professional football, $64-67 \%$ of thigh strains have been located in the posterior thigh, ${ }^{7-8}$ which is consistent with the $65 \%$ posterior thigh strains in our study. However, it is not completely clear from the literature if the risk of thigh strain has increased during recent years or the risk of other injury subtypes such as ankle sprain has diminished.

Table 6 Injury severity elite European professional footballers

\begin{tabular}{lllll}
\hline & Injuries & Absence (days) & $\begin{array}{l}\text { Absence } \\
\text { (training sessions) }\end{array}$ & $\begin{array}{l}\text { Absence } \\
\text { (matches) }\end{array}$ \\
\hline Slight & $182(28 \%)$ & $2.2(0.7)$ & $1.6(1.0)$ & $0.2(0.4)$ \\
Minor & $186(28 \%)$ & $5.3(1.0)$ & $3.4(1.3)$ & $0.8(0.6)$ \\
Moderate & $193(29 \%)$ & $14.6(5.6)$ & $9.7(4.3)$ & $2.8(1.6)$ \\
Major & $97(15 \%)$ & $81.9(54.6)$ & $48.5(35.6)$ & $13.3(9.4)$ \\
Total & $658(100 \%)$ & $18.5(34.2)$ & $11.4(21.0)$ & $3.1(5.8)$ \\
\hline \multicolumn{7}{l}{ Values are number (\%) or mean (SD). }
\end{tabular}




\section{What is already known on this topic}

The risk of injury in elite or professional football is known to be high. In recent years, the number of competitive matches during a season has increased for the top clubs. In the most recent studies, thigh strain has been the single most common football injury.

\section{What this study adds}

The injury incidence differed significantly between teams from different European regions. National team players had a significantly higher match exposure, but no higher risk of injury. The study confirms that thigh strain, typically involving the hamstrings, is the most common injury in professional football.

\section{Methodological considerations}

The full background to the study has been reported elsewhere. ${ }^{25}$ In that editorial, it was concluded that, in previous studies, the methodology is often too sparsely reported and that adequate definitions and detailed knowledge of individual exposure are essential to be able to know the actual risk of injury and to compare different studies. At the highest professional level, it is also important to include exposure and injuries during national team play. This is evident from the present study where more than half of the players were exposed to international duties and $4 \%$ of all injuries occurred under these circumstances.

However, although the total cohort is large, the major weakness of the study is the limited number of teams from each country. The original clubs were selected by UEFA according to their league positions during the spring of the preceding season and their chance of qualifying for the Champions League. However, as the study does not cover all teams in the Champions League and three of the original clubs did not consent or had to be excluded from the study, there is a certain risk of selection bias.

Consequently, the findings may not be applicable to all of the Champions League clubs or other first division teams in the countries included. A few prominent football countries such as Germany and Portugal are not represented in the study, and this should also be kept in mind.

To have a high player participation rate and to respect the integrity of the clubs, all data were coded during computerisation, and no player or club specific results are reported in this study. However, group-wise analyses were performed between teams from different countries or regions, and the most pronounced differences are reported and discussed in this study. One important methodological consideration is that we did not specifically evaluate the inter-rater reliability between the clubs, and it is thus unclear whether there are differences in the diagnoses or diagnostic methods used between the teams that may influence the results. However, to minimise bias concerning the injury diagnoses in this study, all injury types were carefully defined and all club medical team members were provided with a manual containing definitions and examples facilitating optimal recording.

\section{ACKNOWLEDGEMENTS}

We gratefully acknowledge the clubs involved in the study, including the voluntarily participating players and the managerial and coaching staff. The help from the medical personnel and the contact persons are also greatly appreciated: Rodolfo Tavana (AC Millan), Piet Bon (AFC Ajax), Leonard Sash and Gary Lewin (Arsenal FC), Franscesco Benazzo, Franco Combi and PierLuigi Parnofiello (FC Internazionale Milano), Fabrizio Tencone (Juventus FC), Mike Stone (Manchester United FC), Hakim Chalabi (Paris St Germain FC), Cees-Rein vd Hoogenband and Luc van Agt (PSV Eindhoven), Denis Bucher (RC de Lens), Luis Serratossa and Antonio Acedo (Real Madrid CF) and Pierre Rochcongar (Stade Rennais FC). The support of the President, Lennart Johansson, the Technical Director, Andy Roxburgh and the Medical Committee members of UEFA is sincerely appreciated. We also express our gratitude to UEFA, the Swedish Football Association, and the Swedish Sports Confederation (Sports Research Council) for financial support of the study. The help of biostatistician Nadine Karlsson for statistical advice and Dr Peter Cox for correction of the text is also gratefully acknowledged.

\section{Authors' affiliations}

M Waldén, M Hägglund, J Ekstrand, Department of Health and Society, Linköping University, Sweden

Competing interests: none declared

\section{REFERENCES}

1 Árnason A, Gudmundsson A, Dahl HA, et al. Soccer injuries in Iceland. Scand J Med Sci Sports 1996;6:40-5.

2 Árnason A, Sigurdsson SB, Gudmundsson A, et al. Risk factors for injuries in football. Am J Sports Med 2004;32:S5-16.

3 Ekstrand J, Tropp H. The incidence of ankle sprains in soccer. Foot Ankle 1990;11:41-4.

4 Ekstrand J, Waldén $M$, Hägglund $M$. Risk for injury when playing in a national football team. Scand J Med Sci Sports 2004;14:34-8.

5 Ekstrand J, Waldén $M$, Hägglund $M$. A congested football calendar and the well-being of players. Br J Sports Med 2004;38:493-7.

6 Engström B, Forssblad M, Johansson C, et al. Does a major knee injury definitely sideline an elite soccer player? Am J Sports Med 1990;18:101-5.

7 Hawkins RD, Fuller CW. A prospective epidemiological study of injuries in four English professional football clubs. Br J Sports Med 1999;33:196-203.

8 Hawkins RD, Hulse MA, Wilkinson $C$, et al. The association football medical research programme: an audit of injuries in professional football. $\mathrm{Br} J$ Sports Med 2001;35:43-7.

9 Hägglund $M$, Waldén M, Ekstrand J. Exposure and injury risk in Swedish elite football: a comparison between seasons 1982 and 2001. Scand J Med Sci Sports 2003;13:364-70

10 Hägglund $M$, Waldén $M$, Ekstrand J. Injury incidence and distribution in elite football: a prospective study of the Danish and the Swedish top divisions. Scand J Med Sci Sports 2005;15:21-8.

11 Lewin G. The incidence of injuries in an English professional soccer club during one competitive season. Physiotherapy 1989;75:601-5.

12 Waldén M, Hägglund M, Ekstrand J. Injuries in Swedish elite football: a prospective study on injury definitions, risk for injury and injury pattern during 2001. Scand J Med Sci Sports 2005;15:118-25.

13 Woods C, Hawkins R, Hulse M, et al. The Football Association Medical Research Programme: an audit of injuries in professional football-analysis of preseason injuries. Br J Sports Med 2002;36:436-41.

14 Junge A, Chomiak J, Dvorak J. Incidence of football injuries in youth players. Comparison of players from two European regions. Am J Sports Med 2000;28:S47-50

15 Ekstrand J. Soccer injuries and their prevention. Thesis, University of Linköping, Linköping, Sweden, 1982.

16 Orava S. Exertion injuries due to sports and physical exercise. A clinical and statistical study of nontraumatic overuse injuries of the musculoskeletal system of athletes and keep-fit athletes. Thesis, University of Oulu, Oulu, Finland, 1980.

17 Ekstrand J, Gillquist J, Möller M, et al. Incidence of soccer injuries and their relation to training and team success. Am J Sports Med 1983;11:63-7.

18 Nielsen AB, Yde J. Epidemiology and traumatology of injuries in soccer. Am J Sports Med 1989;17:803-7.

19 Berger-Vachon C, Gabard G, Moyen B. Soccer accidents in the French Rhône-Alpes Soccer Association. Sports Med 1986;3:69-77.

20 Ekstrand J, Gillquist J. Soccer injuries and their mechanisms: a prospective study. Med Sci Sports Exerc 1983;5:267-70.

21 Ekstrand J, Nigg BM. Surface-related injuries in soccer. Sports Med 1989;8:56-62.

22 Orchard J. Is there a relationship between ground and climatic conditions and injuries in football? Sports Med 2002;32:419-32.

23 Andersen TE, Engebretsen L, Bahr R. Rule violations as a cause of injuries in male Norwegian professional football. Are the referees doing their job? Am J Sports Med 2004;32:S62-8.

24 Fuller CW, Junge A, Dvorak J. An assessment of football referees' decisions in incidents leading to player injuries. Am J Sports Med 2004;32:S17-22.

25 Ekstrand J, Karlsson J. The risk for injury in football. There is a need for a consensus about definition of the injury and the design of studies [editorial]. Scand J Med Sci Sports 2003;13:147-9. 